\title{
BMJ Open Is neighbourhood walkability related to body mass index among different age groups? A cross-sectional study of Canadian urban areas
}

\author{
Justin Thielman (D , , ${ }^{1}$ Ray Copes, ${ }^{2,3}$ Laura C Rosella (D) , ${ }^{3}$ Maria Chiu, ${ }^{4}$ \\ Heather Manson ${ }^{1,3}$
}

To cite: Thielman J,

Copes R, Rosella LC, et al. Is neighbourhood walkability related to body mass index among different age groups? A crosssectional study of Canadian urban areas. BMJ Open 2019;9:e032475. doi:10.1136/ bmjopen-2019-032475

- Prepublication history for this paper is available online. To view these files, please visit the journal online (http://dx.doi. org/10.1136/bmjopen-2019032475).

MC and HM are joint senior authors.

Received 19 June 2019 Revised 28 0ctober 2019 Accepted 07 November 2019

Check for updates

(c) Author(s) (or their employer(s)) 2019. Re-use permitted under CC BY-NC. No commercial re-use. See rights and permissions. Published by BMJ.

For numbered affiliations see end of article.

Correspondence to Mr Justin Thielman; Justin.Thielman@oahpp.ca

\section{ABSTRACT}

Background Studies of neighbourhood walkability and body mass index (BMI) have shown mixed results, possibly due to biases from self-reported outcomes or differential effects across age groups. Our objective was to examine relationships between walkability and objectively measured BMI in various age groups, in a nationally representative population.

Methods The study population came from the 20072011 Canadian Health Measures Survey, a cross-sectional survey of a nationally representative Canadian population. In our covariate-adjusted analyses, we included survey respondents aged 6-79 who were not pregnant, did not live in rural areas, were not missing data and were not thin/underweight. We used objectively measured height and weight to calculate BMl among adults aged 18-79 and $\mathrm{zBMl}$ among children aged $6-17$. We categorised respondents into walkability quintiles based on their residential Street Smart Walk Score values. We performed linear regression to estimate differences between walkability quintiles in BMI and zBMI. We analysed adults and children overall; age subgroups $6-11,12-17,18-29$, 30-44, 45-64 and 65-79; and sex subgroups.

Results The covariate-adjusted models included 9265 respondents overall. After adjustment, differences between walkability quintiles in BMI and zBMI were small and not statistically significant, except for males aged 6-17 in the second-highest walkability quintile who had significantly lower zBMls than those in the lowest quintile.

Conclusion After accounting for confounding factors, we did not find evidence of a relationship between walkability and BMI in children or adults overall, or in any age subgroup with sexes combined. However, post hoc analysis by sex suggested males aged 6-17 in more walkable areas may have lower zBMls.

\section{INTRODUCTION}

Body mass index (BMI), a measure of body fat or adiposity, is an important risk factor for many chronic diseases. ${ }^{12}$ BMIs from 25.0 to $29.9 \mathrm{~kg} / \mathrm{m}^{2}$ are classified as overweight and $30.0 \mathrm{~kg} / \mathrm{m}^{2}$ and over are classified as obese. ${ }^{13}$ People with BMIs of $25.0 \mathrm{~kg} / \mathrm{m}^{2}$ and over are at increased risk of common and serious chronic

\section{Strengths and limitations of this study}

- This study uses objective measures of walkability and BMI to examine how the relationship between walkability and BMI differs between different age groups.

- This study analyses a large nationally representative Canadian population sample, which allows for stratification by age and adjustment for numerous sociodemographic variables.

- Differences between study participants in variables such as caloric intake, amount of time spent in neighbourhood of residence and preference for living in a more walkable neighbourhood were not accounted for.

- Residents of rural areas and individuals aged younger than 6 years or older than 79 years are not included in the study, so results may not be generalisable to these populations.

illnesses, such as cardiovascular disease, type 2 diabetes and certain cancers. ${ }^{13}$ The prevalence of overweight and obesity, as measured through elevated BMI, has increased across the globe in recent decades. ${ }^{34}$ Elevated BMI is common in the Canadian population; over half of adults and over a quarter of children have BMIs of $25 \mathrm{~kg} / \mathrm{m}^{2}$ or more. ${ }^{56}$

Health interventions that focus on changing individual behaviours have fallen short of reducing the high prevalence of overweight and obesity, which has prompted a focus on the environmental determinants of BMI. ${ }^{7}$ In recent years, public health has focused on walkability, a measure of neighbourhood design that includes residential density, proximity to stores and services, and intersection density. ${ }^{7}$ The underlying hypothesis is that walkable neighbourhoods encourage walking for transportation and other types of physical activity that contribute to reducing adiposity and lowering BMI. ${ }^{8}$ 
Despite the enthusiasm around walkability, research into the relationship between walkability and BMI or overweight and obesity has been mixed, with some studies showing a relationship and others showing minimal effects. ${ }^{910}$ To some extent, this may be the result of differences in analytical methods or in measurement of study variables, such as BMI assessment method. Most studies have relied on self-reported height and weight to estimate BMI, which have been shown to be less accurate than direct measures. ${ }^{41}$ People tend to overestimate height and underestimate weight, resulting in an artificially low BMI. ${ }^{411}$ Failure to account for age differences in the relationship between walkability and BMI may also have contributed to the mixed results. Different studies have focused on specific age groups, such as children, youth, working-age adults and seniors; however, all of these age groups have not been analysed in a single study of walkability and BMI, where differential effects by age could be examined. In addition, many earlier studies of walkability focused on only one or two cities, which may not have been representative of a broader population. Therefore, the objective of our study was to examine associations between walkability and objectively measured BMI and compare associations across a range of age groups, in a nationally representative population.

\section{METHODS}

\section{Study design}

This study was a cross-sectional survey that used cycle 1 (2007-2009) and cycle 2 (2009-2011) of the Canadian Health Measures Survey (CHMS). ${ }^{12} 13$ The CHMS is a national health survey that collects both self-reported and direct measures. It uses a multistage sampling design stratified by geographical region, age and sex. The survey covers $96 \%$ of Canadians, but excludes people in institutions, full-time Canadian Armed Forces members, people living on reserves or other Aboriginal settlements, certain remote regions and the three Canadian territories.

\section{Setting}

The CHMS involves an in-person questionnaire conducted at participants' households, followed by direct measures taken at mobile clinics within $50 \mathrm{~km}$ of their households. ${ }^{12} 13$

\section{Population}

We combined CHMS cycles 1 and 2 to increase sample size. The combined response rate for people who completed both the household questionnaire and visit to the mobile examination centre was $51.7 \%$ in the 2007-2009 CHMS and $55.5 \%$ in the 2009-2011 CHMS. The response rate averaged across both cycles was $53.6 \%$. Respondents were weighted to be nationally representative. Both cycles used the same data collection methods and included respondents with similar characteristics. ${ }^{12}{ }^{13}$ Cycle 1 included people aged 6-79, while cycle 2 included those aged 3-79; for comparability, we excluded children 3-5 years old from cycle 2 before combining the two cycles. When calculating walkability, we used points within censusdefined geographical areas as proxies for residential locations; however, these geographical areas were very large in rural areas and therefore poor proxies for residential locations, so we excluded respondents living in rural areas. Non-rural dwelling was defined as continuous built-up areas of 1000 people or more, with at least 400 people $/ \mathrm{km}^{2} .{ }^{14}$ We also excluded women who were pregnant or missing data on pregnancy because elevated BMI due to pregnancy is not necessarily an indicator of overweight or obesity. We excluded children under 18 who were missing birth dates, as these were needed to calculate BMI-for-age z-scores, and excluded any respondents missing directly measured height or weight, as these were needed to calculate BMIs and BMI z-scores. After these exclusions, our population sample included people aged 6-79, living in non-rural areas, not pregnant, and not missing data on pregnancy, height, weight or birth date if under 18 (figure 1). This is the population described in table 1 and analysed in the unadjusted analyses. Our adjusted analyses also excluded people missing any of the covariates in the models, as well as people classified as thin or underweight (BMI z-score $>2$ SD below the mean for children, $\mathrm{BMI}<18.5 \mathrm{~kg} / \mathrm{m}^{2}$ for adults). This was done because BMIs low enough to be classified thin or underweight are associated with unique health problems, such as chronic respiratory diseases, ${ }^{15}$ that are not hypothesised to be related to walkability.

\section{Walkability data}

Our walkability indicator was the Street Smart Walk Score metric (henceforth referred to as Walk Score) ${ }^{16}$ It is a validated metric that ranges from 0 (low walkability) to 100 (high walkability). ${ }^{17}{ }^{18}$ It is based on the number, variety and proximity of different neighbourhood amenities such as restaurants/bars, parks and schools, as well as street connectivity. The website https://www.redfin. $\mathrm{ca} /$ how-walk-score-works contains more information on the Walk Score methodology. In 2014, we obtained Walk Score values for latitude/longitude coordinates within the census dissemination areas in which CHMS respondents lived. Dissemination areas are designed to cover areas with $400-700$ people. ${ }^{19}$ In non-rural areas, this is small enough to approximate the locations of respondents' residences. We matched dissemination areas and their corresponding Walk Score values to respondents by their postal codes using Statistics Canada's Postal Code Conversion File. ${ }^{20}$

\section{Body mass index}

The CHMS measured participants' weights using a digital scale and their heights using a stadiometer.

For respondents aged 18-79, we calculated BMI as weight in kilograms divided by squared height in metres. For respondents aged 6-17, we used a tool from WHO that calculates BMI-for-age z-score. ${ }^{21}$ 


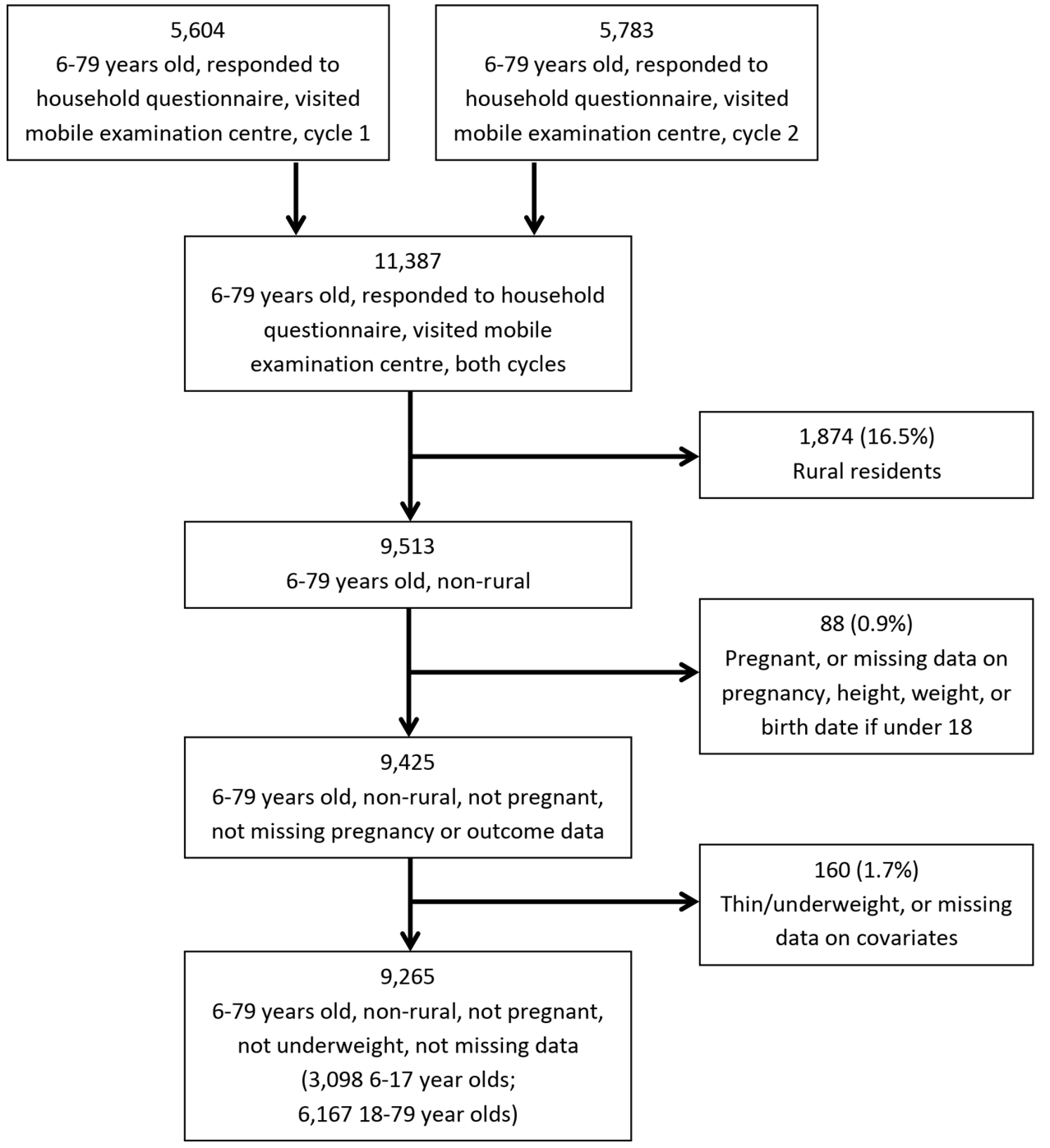

Figure 1 Flow diagram of study participants.

\section{Statistical analysis}

We divided respondents into quintiles based on their survey-weighted Walk Score values. We also log transformed adult BMI to correct for its unequal variability at different Walk Score values, as recommended by a Box-Cox transformation of BMI. We examined the degree of correlation between respondents in the same dissemination areas using the intraclass correlation coefficient. We built both unadjusted and covariate-adjusted linear regression models. Previous studies have shown that age interacts with walkability, ${ }^{10}{ }^{22}$ so we performed subgroup analyses within the following age strata: 6-11, 12-17, 18-29, 30-44, 45-64 and 65-79. These groupings reflected our hypothesis that walkability may have varying effects on the following life stages: child, youth, young adult, early-middle-aged adult, late-middle-aged adult and older retired/semiretired adult. We also performed post hoc subgroup analyses of males and females separately, as sex has also been shown to interact with walkability. ${ }^{23}$ For age groups 6-11 and 12-17, we modelled BMI z-score, adjusting for age, sex, cultural/racial origin, immigration within the past 10 years, household income, fruit/ vegetable consumption and survey cycle. For age groups 18-29, 30-44, 45-64 and 65-79, we modelled $\log$ (BMI), adjusting for all variables listed above, plus marital status, smoking and leisure physical activity. We identified these variables as the most important confounders based on earlier research. ${ }^{23-28}$ After modelling $\log (\mathrm{BMI})$, we reverse transformed the mean predicted $\log (\mathrm{BMI})$ values and their CIs to obtain the average predicted BMI in each Walk Score quintile. In all analyses, we used the bootstrap survey weights that were provided with the CHMS data to account for the complex survey design. We performed all analyses using SAS V.9.4.

\section{Patient and public involvement}

Participant data are from a survey previously conducted by Statistics Canada. All participant identifiers had been removed from the data, so it was not possible to involve participants in the design of the study or dissemination of the results. 
Table 1 Characteristics of Canada-wide study population, overall and by Street Smart Walk Score quintiles, $n=9425$

\begin{tabular}{|c|c|c|c|c|c|c|}
\hline Variable & Total & $\begin{array}{l}\text { Lowest walk } \\
\text { score } \\
\text { Q1: 0-23 }\end{array}$ & $\begin{array}{l}\text { Walk score } \\
\text { Q2: 24-40 }\end{array}$ & $\begin{array}{l}\text { Walk score } \\
\text { Q3: 41-58 }\end{array}$ & $\begin{array}{l}\text { Walk score } \\
\text { Q4: 59-79 }\end{array}$ & $\begin{array}{l}\text { Highest walk } \\
\text { score } \\
\text { Q5: 80-100 }\end{array}$ \\
\hline \multicolumn{7}{|l|}{ Age category (\%) } \\
\hline $6-11$ & 7.3 & 9.9 & 8.4 & 7.6 & 6.3 & 4.8 \\
\hline $12-17$ & 8.5 & 8.8 & 11.0 & 9.3 & 7.7 & 6.2 \\
\hline $18-29$ & 19.2 & 16.8 & 19.4 & 16.7 & 21.0 & 22.1 \\
\hline $30-44$ & 23.8 & 23.8 & 20.9 & 24.4 & 20.5 & 29.1 \\
\hline $45-64$ & 30.9 & 32.1 & 31.4 & 31.2 & 31.2 & 28.9 \\
\hline $65-79$ & 10.2 & 8.7 & 9.0 & 10.8 & 13.3 & 8.9 \\
\hline \multicolumn{7}{|l|}{ Sex (\%) } \\
\hline Male & 50.3 & 48.8 & 48.0 & 49.2 & 51.6 & 53.7 \\
\hline Female & 49.7 & 51.2 & 52.0 & 50.8 & 48.4 & 46.3 \\
\hline \multicolumn{7}{|l|}{ Cultural/racial origin (\%) } \\
\hline White & 75.7 & 86.3 & 81.3 & 73.5 & 68.9 & 69.2 \\
\hline Black & 3.0 & 1.4 & 2.2 & 3.9 & 4.5 & 2.9 \\
\hline Asian & 7.3 & 2.2 & 5.2 & 5.6 & 9.4 & 13.7 \\
\hline South Asian & 4.8 & 2.5 & 4.7 & 5.9 & 8.2 & 2.5 \\
\hline Other/NA* & 9.2 & 7.6 & 6.6 & 11.0 & 8.9 & 11.6 \\
\hline \multicolumn{7}{|c|}{ Immigrated to Canada in previous 10 years (\%) } \\
\hline Yes & 9.9 & 5.0 & 5.0 & 10.7 & 11.7 & 16.7 \\
\hline No & 90.1 & 95.0 & 95.0 & 89.3 & 88.3 & 83.3 \\
\hline \multicolumn{7}{|l|}{ Marital status (\%) } \\
\hline Partnered & 52.7 & 57.0 & 54.8 & 53.2 & 51.8 & 47.3 \\
\hline Not partnered & 47.3 & 43.0 & 45.2 & 46.8 & 48.2 & 52.7 \\
\hline \multicolumn{7}{|c|}{ Smoking status (age 12+ only) (\%) } \\
\hline Daily/non-daily smoker & 19.6 & 18.2 & 17.9 & 19.9 & 20.6 & 21.1 \\
\hline Former/never smoker & 80.4 & 81.8 & 82.1 & 80.1 & 79.4 & 78.9 \\
\hline
\end{tabular}

Household income†'f

\$C1000 increments

$69000(60000) \quad 80000(60000) 79000(60000) 69000(55000) 59000(55000) 55000(60000)$

\begin{tabular}{|c|}
\hline \\
\hline times per day fruits or \\
\hline
\end{tabular}

vegetables eaten $\ddagger$

Energy expenditure on leisure physical activity $\ddagger$ (age 12+ only)

\begin{tabular}{|c|c|c|c|c|c|c|}
\hline $\mathrm{kcal} / \mathrm{kg} /$ day & $1.4(2.4)$ & $1.4(2.4)$ & $1.4(2.3)$ & $1.3(2.4)$ & $1.3(2.3)$ & $1.6(2.3)$ \\
\hline BMI‡ (age 18+) & $26.2(6.5)$ & $26.9(6.0)$ & $26.5(6.9)$ & $26.5(6.7)$ & $26.2(6.6)$ & $24.9(6.5)$ \\
\hline BMI z-scoreł (age 6-17) & $0.4(1.7)$ & $0.5(1.5)$ & $0.3(1.9)$ & $0.3(1.6)$ & $0.3(1.6)$ & $0.3(1.6)$ \\
\hline
\end{tabular}

*'Other' includes people who reported Latin American, Southeast Asian, Arab, West Asian, Other or Multiple; 'NA' includes people not asked about cultural/racial origin, which includes anyone who self-identified as Aboriginal.

tIncomes rounded to nearest \$C1000.00.

$\ddagger$ Cell numbers are medians (IQRs). All other cell numbers are percentages that have been weighted using Canadian Health Measures

Survey sample weights, unless otherwise specified.

BMI, body mass index; Q, quintile.

\section{RESULTS}

\section{Population}

There were 9425 people aged 6-79, living in non-rural areas, not pregnant, and not missing data on pregnancy, height, weight or birth date if under 18 in our sample. Table 1 shows the sociodemographic characteristics of the overall sample, as well as within each Walk Score quintile. The population analysed in our multivariable analysis, which also excluded people who were thin/underweight or missing covariates, was 9265 , including 3098 children aged 6-17 and 6167 adults aged 18-79 (figure 1). The intraclass correlation coefficient for respondents with the same dissemination area was 0.05 , indicating low correlation; we, therefore, did not account for clustering by dissemination area in the analyses. 
Table 2 Unadjusted and adjusted differences from lowest Street Smart Walk Score quintile in BMI z-score, participants aged $6-17$, overall and by age group $(n=3098)$

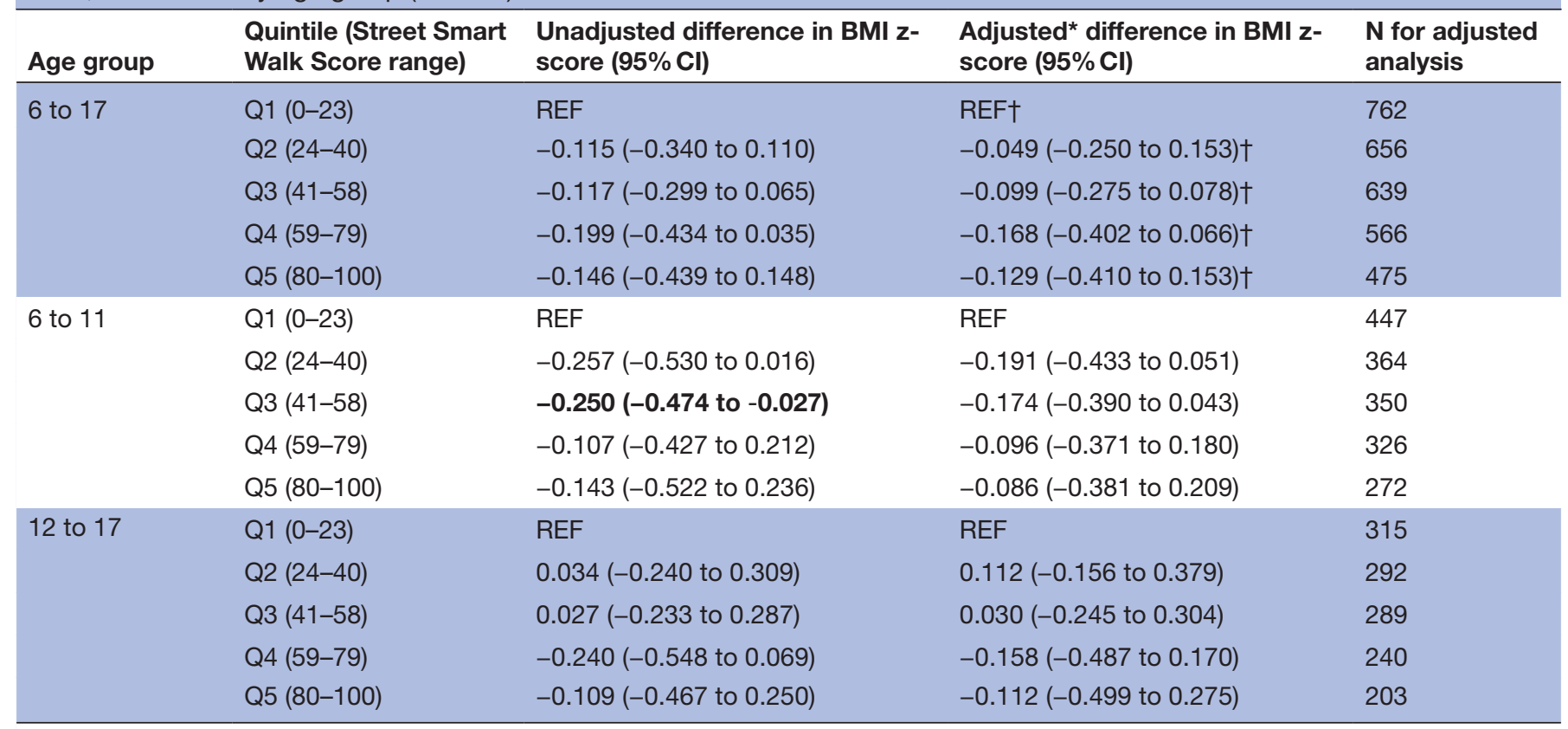

Statistically significant estimates at $\mathrm{p}<0.05$ in bold. $\mathrm{Q} 1=1$ st Walk Score quintile, $\mathrm{Q} 2=2$ nd Walk Score quintile, $\mathrm{Q} 3=3 \mathrm{rd}$ Walk Score quintile, Q4=4th Walk Score quintile, Q5=5th Walk Score quintile.

*Estimates adjusted for sex, cultural/racial origin, immigration to Canada in the past 10 years, household income quintile, fruit/vegetable consumption and survey cycle.

†Analyses also adjusted for age category. Walk Score values from 2014. Remaining variables from 2007 to 2011 Canadian Health Measures Survey.

BMI, body mass index.

\section{BMI z-score}

Among those aged 6-17years overall, children in each of the higher Walk Score quintiles had slightly lower average BMI z-scores than those in the lowest Walk Score quintile; however, none of these differences were statistically significant, both before and after adjusting for covariates (table 2). In the unadjusted analysis, respondents 6-11years old in the third Walk Score quintile had significantly lower BMI z-scores than those in the lowest Walk Score quintile, on average; however, this association was no longer significant after adjusting for age, sex, cultural/racial origin, immigration, household income and fruit/vegetable consumption (table 2). In the subgroup analysis by sex, males aged $6-17$ in higher Walk Score quintiles had lower average BMI z-scores, a difference not observed among females (table 3). The difference among males in the fourth quintile was statistically significant and remained significant after adjusting for age, cultural/racial origin, immigration, household income and fruit/vegetable consumption. There were no other significant associations between any Walk Score quintiles among children under age 18, both before and after adjusting for covariates.

\section{$\log (\mathrm{BMI})$}

In the unadjusted analysis of all adults aged 18-79, people in the highest Walk Score quintile had significantly lower $\log (\mathrm{BMI})$ values than those in the lowest quintile (table 4 ).
The highest quintile also had significantly lower $\log (\mathrm{BMI})$ values among the subgroup of adults aged 18-29, and among the male and female subgroups (tables 4 and 5). However, all of these associations were no longer significant after adjusting for age, sex, cultural/racial origin, immigration, household income, marital status, smoking, fruit/vegetable consumption and leisure physical activity. While average $\log (\mathrm{BMI}) \mathrm{s}$ were slightly lower in the highest Walk Score quintiles in all other comparisons among adults, the differences were not statistically significant, both before and after covariate adjustment.

\section{DISCUSSION}

\section{Summary}

After adjusting for relevant covariates, our study did not identify a significant relationship between neighbourhood walkability and objectively measured BMI in the overall study population or in any of the age subgroups, although, while not statistically significant, average BMI was slightly lower in the highest walkability quintile among adults overall and in all adult subgroups. In addition, in our post hoc analysis of sex subgroups, there was evidence that males aged 6-17 living in higher Walk Score quintiles had lower BMI z-scores than those in the lowest quintile, on average.

A number of earlier studies that examined the built environment and body mass showed null results. A longitudinal 
Table 3 Unadjusted and adjusted differences from lowest Street Smart Walk Score quintile in BMI z-score, participants aged $6-17$, by $\operatorname{sex}(n=3098)$

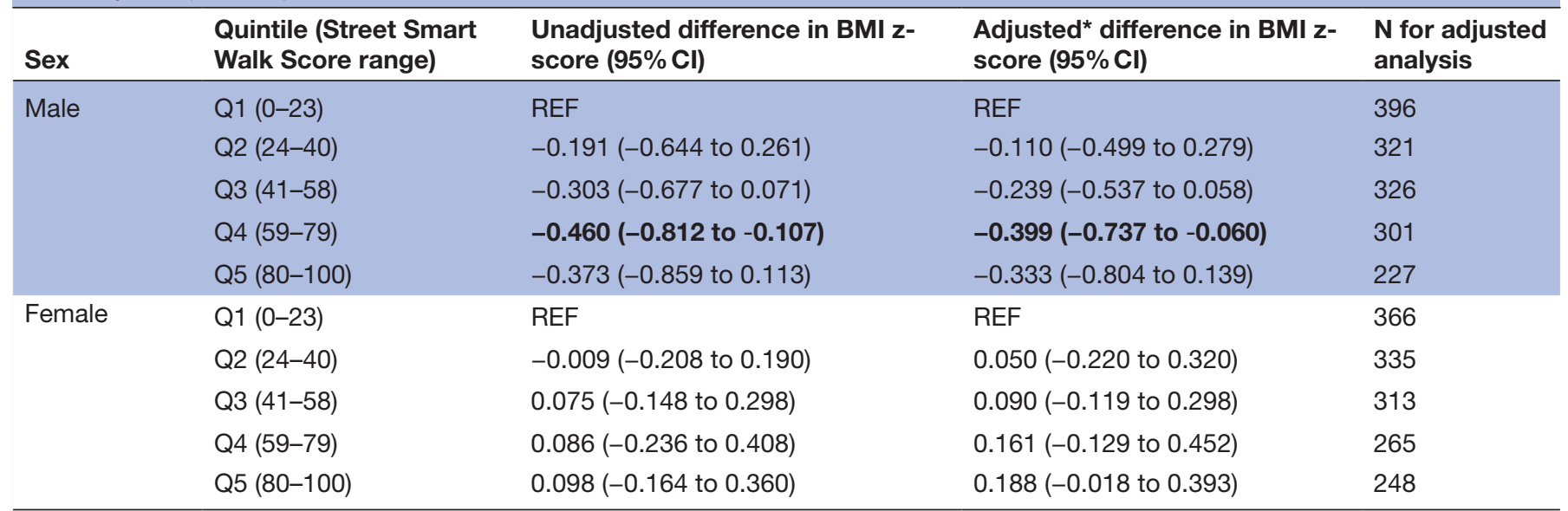

Statistically significant estimates at $\mathrm{p}<0.05$ in bold. $\mathrm{Q} 1=1$ st Walk Score quintile, $\mathrm{Q} 2=2 \mathrm{nd}$ Walk Score quintile, Q3=3rd Walk Score quintile, Q4=4th Walk Score quintile, Q5=5th Walk Score quintile.

${ }^{*}$ Estimates adjusted for age category, cultural/racial origin, immigration to Canada in the past 10 years, household income quintile, fruit/vegetable consumption and survey cycle. Walk Score values from 2014. Remaining variables from 2007 to 2011 Canadian Health Measures Survey.

$\mathrm{BMI}$, body mass index.

study of Australian adults did not find an association between walkability and self-reported weight change. ${ }^{8}$ An American longitudinal study saw no significant change in objectively measured BMI associated with a 1 SD change in walkability index. ${ }^{27}$ Conversely, several previous studies have identified statistically significant relationships. A study of adults aged 30-64 in Southern Ontario, Canada, found that people in the two highest quintiles of walkability had no change in prevalence of self-reported overweight and obesity over 11 years, while people in the lowest three quintiles had increased prevalence of overweight and obesity over this time period. ${ }^{26}$ Another study in Ontario found that people in the highest walkability quintile had lower self-reported BMIs than people in the lower quintiles. $^{29}$ Ontario is a province of Canada that includes over one-third of Canada's population, so the aforementioned positive results are based on populations similar to our study population. Perhaps our discordant results are due to our use of objective measures of BMI, rather than selfreport. Self-reported BMI values are prone to biases, ${ }^{4}$ so it is possible that mitigating these biases resulted in our nonsignificant results.

Findings from other Canadian studies were more mixed. Pouliou and colleagues found an association between walkability and self-reported BMI in Vancouver, but not in Toronto. ${ }^{30}$ Glazier and colleagues found that people in the lowest walkability quintile had higher odds of self-reported overweight and obesity combined, but did not have higher odds of obesity alone. ${ }^{31}$ A longitudinal study by Wasfi and colleagues found that men who moved to more walkable areas had decreased BMI trajectories, while men who moved to less walkable areas had increased BMI trajectories; however, no relationship between walkability and BMI was found among women. ${ }^{23}$ After adjusting for confounders, our study did not show a significant relationship between walkability and BMI among adult males or females; however, we did find evidence of a lower average BMI z-score among male children in higher Walk Score quintiles, which did not show up among female children. Firm conclusions cannot be drawn from this finding, as it was the result of a post hoc subgroup analysis. However, future research should further explore how the relationship between walkability and BMI z-score may differ between males and females.

Studies of walkability and BMI have had less consistent findings than studies of walkability and physical activity, which have shown that people in more walkable areas tend to do more walking for transportation and more physical activity. ${ }^{9} 1032$ This may seem counterintuitive, as one might assume that higher physical activity should lower BMI. However, BMI is influenced by many factors of which physical activity is only one. ${ }^{24}$ The higher physical activity associated with higher walkability may not be enough to reduce BMI by a measurable amount, given the multitude of other determinants of BMI. ${ }^{33}$ For instance, diet may influence BMI to a greater extent than physical activity. ${ }^{34}$ According to the Walking Calorie Burn Calculator by Shapesense, a 180-pound person who walks $1 \mathrm{~km}$ in 15 min burns only 71 calories. ${ }^{35}$

\section{Strengths and limitations}

Our study has numerous strengths, including its use of objective measures of walkability and BMI, its large Canada-wide study population and its inclusion of many sociodemographic characteristics. There are few studies of walkability that have used objective measures of BMI in a nationally representative population. There are also several limitations that should be considered when interpreting our findings. There may be residual confounding 
Table 4 Unadjusted and covariate-adjusted differences from lowest Street Smart Walk Score quintile in log(BMI), participants aged $18-79$, overall and by age group $(n=6167)$

\begin{tabular}{|c|c|c|c|c|c|}
\hline Age group & $\begin{array}{l}\text { Quintile (Street Smart } \\
\text { Walk Score range) }\end{array}$ & $\begin{array}{l}\text { Unadjusted difference in } \\
\text { log(BMI) }(95 \% \mathrm{Cl})\end{array}$ & $\begin{array}{l}\text { Adjusted* difference in } \\
\text { log(BMI) }(95 \% \mathrm{Cl})\end{array}$ & $\begin{array}{l}\text { Mean predicted BMI } \\
(95 \% \mathrm{Cl})\end{array}$ & $\begin{array}{l}\mathbf{N} \text { for } \\
\text { adjusted } \\
\text { analysis }\end{array}$ \\
\hline \multirow[t]{4}{*}{18 to 79} & Q1 (0-23) & REF & REF† & 27.7 (26.8 to 28.6 ) & 1265 \\
\hline & Q2 (24-40) & $-0.014(-0.037$ to 0.010$)$ & $-0.002(-0.025$ to 0.021$) \dagger$ & 27.5 (26.6 to 28.5$)$ & 1101 \\
\hline & Q3 (41-58) & $-0.015(-0.043$ to 0.014$)$ & $-0.004(-0.030$ to 0.022$) \dagger$ & 27.4 (26.4 to 28.4$)$ & 1276 \\
\hline & Q4 (59-79) & $-0.025(-0.055$ to 0.006$)$ & $-0.002(-0.027$ to 0.024$) \dagger$ & 27.3 (26.2 to 28.3 ) & 1311 \\
\hline \multirow[t]{5}{*}{18 to 29} & Q1 (0-23) & REF & REF & 25.9 (24.3 to 27.5$)$ & 196 \\
\hline & Q2 (24-40) & $-0.025(-0.087$ to 0.037$)$ & $-0.027(-0.093$ to 0.040$)$ & 25.2 (23.2 to 27.3 ) & 197 \\
\hline & Q3 (41-58) & $-0.028(-0.098$ to 0.043$)$ & $-0.033(-0.101$ to 0.035$)$ & 25.1 (23.0 to 27.4$)$ & 232 \\
\hline & Q4 (59-79) & $-0.039(-0.100$ to 0.023$)$ & $-0.025(-0.083$ to 0.034$)$ & 25.2 (23.2 to 27.3 ) & 275 \\
\hline & Q5 (80-100) & $-0.052(-0.096$ to -0.008$)$ & $-0.035(-0.083$ to 0.013$)$ & 24.8 (23.1 to 26.8$)$ & 229 \\
\hline \multirow{2}{*}{30 to 44} & Q4 (59-79) & $-0.015(-0.071$ to 0.041$)$ & $0.010(-0.055$ to 0.076$)$ & 27.2 (25.6 to 29.0$)$ & 353 \\
\hline & Q5 (80-100) & $-0.052(-0.110$ to 0.006$)$ & $-0.017(-0.080$ to 0.046$)$ & 26.3 (24.7 to 27.9$)$ & 371 \\
\hline \multirow[t]{5}{*}{45 to 64} & Q1 (0-23) & REF & REF & 28.4 (27.2 to 29.6$)$ & 403 \\
\hline & Q2 (24-40) & $-0.017(-0.047$ to 0.013$)$ & $-0.001(-0.035$ to 0.032$)$ & 28.3 (27.1 to 29.7 ) & 345 \\
\hline & Q3 (41-58) & $-0.020(-0.069$ to 0.029$)$ & $-0.007(-0.052$ to 0.038$)$ & 28.0 (26.5 to 29.7$)$ & 431 \\
\hline & Q4 (59-79) & $-0.017(-0.060$ to 0.025$)$ & $0.004(-0.034$ to 0.041$)$ & 28.2 (26.7 to 29.8$)$ & 405 \\
\hline & Q5 (80-100) & $-0.041(-0.088$ to 0.005$)$ & $-0.021(-0.064$ to 0.022$)$ & 27.3 (25.7 to 28.9$)$ & 409 \\
\hline 65 to 79 & Q1 (0-23) & REF & REF & 28.6 (27.3 to 30.0$)$ & 212 \\
\hline
\end{tabular}

Statistically significant estimates at $\mathrm{p}<0.05$ in bold. Q1=1st Walk Score quintile, Q2=2nd Walk Score quintile, Q3=3rd Walk Score quintile, Q4=4th Walk Score quintile, Q5=5th Walk Score quintile.

*Estimates adjusted for sex, cultural/racial origin, immigration to Canada in the past 10 years, household income quintile, fruit/vegetable consumption, leisure physical activity, marital status, smoking status and survey cycle.

†Analyses of all respondents also adjusted for age category. Walk Score values from 2014. Remaining variables from 2007 to 2011 Canadian Health Measures Survey.

BMI, body mass index.

from unmeasured covariates, including differences between quintiles in average caloric intake, the food environment or length of time exposed to residential neighbourhoods. ${ }^{36}$ We were also unable to account for differences in exposure to non-residential areas, such as workplace neighbourhoods, which may also impact BMI. In addition, there was a time lag between the collection of height and weight data from the CHMS in 2007-2011 and calculation of Walk Score values in 2014. However, major changes in Walk Score quintiles are unlikely to have occurred during this time gap, so we do not expect the time difference to impact the results. Likewise, we do not expect the age of the study data, the oldest of which is from 2007, to impact study findings. The relationship between walkability and health outcomes, such as BMI, is unlikely to have changed since 2007. In addition, this was a cross-sectional study and therefore cannot be used to draw conclusions about a causal relationship. Finally, study results may not be generalisable to children younger than 6 or rural residents.

Despite the mixed results from studies of walkability and BMI, the potential health benefits of increasing walkability should continue to be investigated. Physical activity appears to improve health regardless of whether it results in weight loss. ${ }^{37} 38$ While elevated BMI is correlated with overall mortality and with several chronic diseases, ${ }^{3}{ }^{15}$ it has limitations as a risk factor for poor health. The association between BMI and mortality is stronger among some populations than others. For instance, it is stronger among younger adults than among older adults. ${ }^{1}$ Other measures of adiposity, such as waist circumference, may be better indicators of 
Table 5 Unadjusted and adjusted differences from lowest Street Smart Walk Score quintile in log(BMI), participants aged 18-79, by sex $(n=6167)$

\begin{tabular}{|c|c|c|c|c|c|}
\hline Sex & $\begin{array}{l}\text { Quintile (Street Smart } \\
\text { Walk Score range) }\end{array}$ & $\begin{array}{l}\text { Unadjusted difference in } \\
\log (\mathrm{BMI})(95 \% \mathrm{Cl})\end{array}$ & $\begin{array}{l}\text { Adjusted }{ }^{*} \text { difference in } \\
\text { log(BMI) }(95 \% \mathrm{Cl})\end{array}$ & $\begin{array}{l}\text { Mean predicted } \\
\text { BMI }(95 \% \mathrm{Cl})\end{array}$ & $\begin{array}{l}\mathrm{N} \text { for adjusted } \\
\text { analysis }\end{array}$ \\
\hline \multirow[t]{3}{*}{ Male } & Q1 (0-23) & REF & REF & 28.2 (27.1 to 29.3 ) & 577 \\
\hline & Q3 (41-58) & $-0.012(-0.046$ to 0.022$)$ & $-0.002(-0.033$ to 0.028$)$ & 27.7 (26.6 to 28.9 ) & 600 \\
\hline & Q4 (59-79) & $-0.020(-0.062$ to 0.023$)$ & $0.001(-0.033$ to 0.034$)$ & 27.6 (26.4 to 28.8$)$ & 595 \\
\hline \multirow{4}{*}{ Female } & Q2 (24-40) & $-0.005(-0.034$ to 0.025$)$ & $0.006(-0.018$ to 0.030$)$ & 27.4 (26.2 to 28.7$)$ & 583 \\
\hline & Q3 (41-58) & $-0.018(-0.057$ to 0.021$)$ & $-0.007(-0.042$ to 0.027$)$ & 27.1 (25.5 to 28.7$)$ & 676 \\
\hline & Q4 (59-79) & $-0.031(-0.064$ to 0.002$)$ & $-0.002(-0.038$ to 0.033$)$ & 27.0 (25.6 to 28.5$)$ & 716 \\
\hline & Q5 (80-100) & $-0.062(-0.099$ to -0.024$)$ & $-0.023(-0.052$ to 0.007$)$ & 26.1 (24.8 to 27.5$)$ & 596 \\
\hline
\end{tabular}

Statistically significant estimates at $\mathrm{p}<0.05$ in bold. $\mathrm{Q} 1=1$ st Walk Score quintile, $\mathrm{Q} 2=2 \mathrm{nd}$ Walk Score quintile, Q3=3rd Walk Score quintile, Q4=4th Walk Score quintile, Q5=5th Walk Score quintile.

*Estimates adjusted for age category, cultural/racial origin, immigration to Canada in the past 10 years, household income quintile, fruit/vegetable consumption, leisure physical activity, marital status, smoking status and survey cycle. Walk Score values from 2014 Remaining variables from 2007 to 2011 Canadian Health Measures Survey.

BMI, body mass index.

metabolic risk than BMI. ${ }^{39}$ One study found that women in more walkable areas had lower odds of abdominal obesity measured by waist circumference, but no significant difference in overall obesity measured by BMI. ${ }^{40}$ A longitudinal study found that changes in walkability were associated with certain cardiometabolic risk factors, but not with BMI. ${ }^{27}$ Future studies of walkability should directly examine the chronic diseases associated with insufficient physical activity, such as type 2 diabetes and cardiovascular disease. Given the established link between physical activity and type 2 diabetes and cardiovascular disease ${ }^{37} 38$ highly walkable areas may reduce risk of these diseases by increasing physical activity levels.

\section{CONCLUSIONS}

Our study did not identify significant associations between neighbourhood walkability and BMI, overall or in any age group, after adjustment for a variety of confounders, although, in our post hoc analysis of sex subgroups, there appeared to be a significant association between walkability and BMI z-score among males aged 6-17. Future studies are needed to explore whether a relationship exists among boys, but not girls. Our mostly non-significant findings may reflect a relatively limited influence of moderately increased physical activity on BMI in the absence of a difference in other factors, such as diet. However, previous research has linked walkability with physical activity, which may have health benefits independent of BMI. ${ }^{37} 38$ Future studies should investigate the relationship between walkability and diabetes or cardiovascular disease. If well-designed studies identify associations with these common chronic diseases, this will strengthen the evidence for improving overall health by increasing walkability.

Author affiliations

${ }^{1}$ Health Promotion, Chronic Disease and Injury Prevention, Public Health Ontario, Toronto, Ontario, Canada

${ }^{2}$ Environmental and Occupational Health, Public Health Ontario, Toronto, Ontario, Canada

${ }^{3}$ Dalla Lana School of Public Health, University of Toronto, Toronto, Ontario, Canada ${ }^{4}$ Institute of Health Policy, Management and Evaluation, University of Toronto, Toronto, Ontario, Canada

\section{Twitter Laura C Rosella @LauraCRosella}

Acknowledgements Access and support for using the Canadian Health Measures Survey was provided by Statistics Canada's Research Data Centre Program. Street Smart Walk Score values were provided by Redfin's Walk Score.

Contributors JT, RC, LCR, MC and HM contributed to conceptualising and designing the study, planning analytical methods, and analysing and interpreting statistical output. JT conducted the literature review, statistical analysis and drafted the manuscript. JT, RC, LCR, MC and HM reviewed the manuscript for intellectual content, made revisions as needed and approved the final version for publication. JT, RC, LCR, MC and HM agree to be accountable for this work and to ensure that questions relating to the work are investigated and resolved.

Funding Financial support for this study was provided to all authors by Public Health Ontario through an annual peer-reviewed competitive Project Initiation Fund (PIF) (2013-14-019).

Disclaimer The opinions, results, and conclusions reported in this paper are those of the authors and are independent from the funding source. The study sponsor had no role in the study design; collection, analysis or interpretation of data; report writing or review; approval of the manuscript; or the decision to submit for publication.

Competing interests None declared.

Patient consent for publication Not required.

Ethics approval The Ethics Review Board of Public Health Ontario granted ethics approval after reviewing our study protocol. Statistics Canada's Research Data Centre granted access to the CHMS after reviewing our application and study protocol. 
Provenance and peer review Not commissioned; externally peer reviewed.

Data availability statement Data may be obtained from a third party and are not publicly available. The Canadian Health Measures Survey data are de-identified participant data, available upon successful application to Statistics Canada's Research Data Centre program: https://www.statcan.gc.ca/eng/rdc/indexStreet Smart Walk Score $\circledR$ values are geocoded walkability data available from Redfin's Walk Score: https://www.redfin.ca/how-walk-score-works

Open access This is an open access article distributed in accordance with the Creative Commons Attribution Non Commercial (CC BY-NC 4.0) license, which permits others to distribute, remix, adapt, build upon this work non-commercially, and license their derivative works on different terms, provided the original work is properly cited, appropriate credit is given, any changes made indicated, and the use is non-commercial. See: http://creativecommons.org/licenses/by-nc/4.0/.

\section{ORCID iDs}

Justin Thielman http://orcid.org/0000-0002-7276-7396

Laura C Rosella http://orcid.org/0000-0003-4867-869X

\section{REFERENCES}

1 Bhaskaran K, Dos-Santos-Silva I, Leon DA, et al. Association of BMI with overall and cause-specific mortality: a population-based cohort study of 3.6 million adults in the UK. Lancet Diabetes Endocrinol 2018;6:944-53.

2 Vanasse A, Demers M, Hemiari A, et al. Obesity in Canada: where and how many? Int J Obes 2006;30:677-83.

3 The GBD 2015 Obesity Collaborators. Health effects of overweight and obesity in 195 countries over 25 years. $N$ Engl J Med 2017;377:13-27.

4 NCD Risk Factor Collaboration. Trends in adult body-mass index in 200 countries from 1975 to 2014: a pooled analysis of 1698 population-based measurement studies with 19.2 million participants. Lancet 2016;387:1377-96.

5 Statistics Canada. Table 13-10-0795-01 Measured children and youth body mass index (BMI) (World Health Organization classification), by age group and sex, Canada and provinces, Canadian Community Health Survey-nutrition [Internet], 2018. Available: https://www150.statcan.gc.ca/t1/tbl1/en/tv.action?pid= 1310079501 [Accessed 17 Dec 2018].

6 Statistics Canada. Table 13-10-0794-01 Measured adult body mass index (BMI) (World Health Organization classification), by age group and sex, Canada and provinces, Canadian Community Health Survey-nutrition [Internet], 2018. Available: https://www150.statcan gc.ca/t1/tbl1/en/tv.action?pid=1310079401 [Accessed 17 Dec 2018].

7 Sallis JF, Floyd MF, Rodríguez DA, et al. Role of built environments in physical activity, obesity, and cardiovascular disease. Circulation 2012:125:729-37.

8 Koohsari MJ, Oka K, Shibata A, et al. Associations of neighbourhood walkability indices with weight gain. Int J Behav Nutr Phys Act 2018;15.

9 Mackenbach JD, Rutter H, Compernolle S, et al. Obesogenic environments: a systematic review of the association between the physical environment and adult weight status, the spotlight project. BMC Public Health 2014;14:233.

10 James $P$, Kioumourtzoglou M-A, Hart JE, et al. Interrelationships between walkability, air pollution, greenness, and body mass index. Epidemiology 2017;28:780-8.

11 Yun S, Zhu B-P, Black W, et al. A comparison of national estimates of obesity prevalence from the behavioral risk factor surveillance system and the National Health and Nutrition Examination Survey. Int J Obes 2006;30:164-70.

12 Statistics Canada. Canadian Health Measures Survey (CHMS) data user guide: cycle 1 [Internet], 2011. Available: http://www23.statcan. gc.ca/imdb-bmdi/document/5071_D2_T1_V1-eng.htm [Accessed 21 Dec 2017].

13 Statistics Canada. Canadian Health Measures Survey (CHMS): detailed information for August 2009 to November 2011 (cycle 2) [Internet], 2012. Available: http://www23.statcan.gc.ca/imdb/p2SV. pl?Function=getSurvey\&ld=62444\#a4 [Accessed 23 May 2019].

14 Statistics Canada. Urban area (UA) [Internet], 2009. Available: http:// www12.statcan.gc.ca/census-recensement/2006/ref/dict/geo049eng.cfm [Accessed 8 Mar 2016].

15 Flegal KMet al. Excess deaths associated with underweight, overweight, and obesity. JAMA 2005;293:1861-7.
16 Walk Score. Walk Score methodology [Internet], 2012. Available: https://www.walkscore.com/methodology.shtml [Accessed 8 Mar 2016].

17 Duncan DT, Aldstadt J, Whalen J, et al. Validation of Walk Score for estimating neighborhood walkability: an analysis of four US metropolitan areas. Int J Environ Res Public Health 2011;8:4160-79.

18 Carr LJ, Dunsiger SI, Marcus BH. Walk Score ${ }^{\mathrm{TM}}$ as a global estimate of neighborhood walkability. Am J Prev Med 2010;39:460-3.

19 Statistics Canada. Dissemination area (DA) - census dictionary [Internet], 2012. Available: https://www12.statcan.gc.ca/censusrecensement/2011/ref/dict/geo021-eng.cfm [Accessed 3 Jul 2016].

20 Statistics Canada. Postal CodeOM Conversion File (PCCF), reference guide, 2013. Statistics Canada catalogue no. 92-154-G [Internet], 2013. Available: http://www5.statcan.gc.ca/olc-cel/olc.action?Objld= 92-154-G\&ObjType=2\&lang=en\&limit=0 [Accessed 8 Mar 2016].

21 World Health Organization. Growth reference 5-19 years [Internet], 2015. Available: http://www.who.int/growthref/tools/en/ [Accessed 21 Dec 2017].

22 Thielman J, Manson H, Chiu M, et al. Residents of highly walkable neighbourhoods in Canadian urban areas do substantially more physical activity: a cross-sectional analysis. CMAJ Open 2016;4:E720-8.

23 Wasfi RA, Dasgupta K, Orpana $\mathrm{H}$, et al. Neighborhood walkability and body mass index trajectories: longitudinal study of Canadians. Am J Public Health 2016;106:934-40.

24 Hales CM, Fryar CD, Carroll MD, et al. Differences in obesity prevalence by demographic characteristics and urbanization level among adults in the United States, 2013-2016. JAMA 2018;319:2419-29.

25 Ford ES, Mokdad AH. Epidemiology of obesity in the Western Hemisphere. J Clin Endocrinol Metab 2008;93:s1-8.

26 Creatore MI, Glazier RH, Moineddin R, et al. Association of neighborhood walkability with change in overweight, obesity, and diabetes. JAMA 2016;315.

27 Braun LM, Rodriguez DA, Song Y, et al. Changes in walking, body mass index, and cardiometabolic risk factors following residential relocation: longitudinal results from the CARDIA study. $J$ Transp Health 2016;3:426-39.

28 Chiu M, Rezai M-R, Maclagan LC, et al. Moving to a highly walkable neighborhood and incidence of hypertension: a propensity-score matched cohort study. Environ Health Perspect 2016;124:754-60.

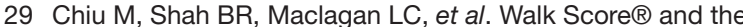
prevalence of utilitarian walking and obesity among Ontario adults: a cross-sectional study. Health Rep 2015;26:3-10.

30 Pouliou T, Elliott SJ. Individual and socio-environmental determinants of overweight and obesity in urban Canada. Health Place 2010;16:389-98.

31 Glazier RH, Creatore MI, Weyman JT, et al. Density, destinations or both? A comparison of measures of walkability in relation to transportation behaviors, obesity and diabetes in Toronto, Canada. PLoS One 2014;9:e85295.

32 Mayne SL, Auchincloss AH, Michael YL. Impact of policy and built environment changes on obesity-related outcomes: a systematic review of naturally occurring experiments. Obes Rev 2015;16:362-75.

33 Dwyer-Lindgren L, Freedman G, Engell RE, et al. Prevalence of physical activity and obesity in US counties, 2001-2011: a road map for action. Popul Health Metr 2013;11:7.

34 Miller WC, Koceja DM, Hamilton EJ. A meta-analysis of the past 25 years of weight loss research using diet, exercise or diet plus exercise intervention. Int J Obes 1997;21:941-7.

35 Daley J. Walking Calorie Burn Calculator. Shapesense [Internet], 2019. Available: http://www.shapesense.com/fitness-exercise/ calculators/walking-calorie-burn-calculator.shtml [Accessed 8 Feb 2019]

36 Rundle A, Neckerman KM, Freeman L, et al. Neighborhood food environment and walkability predict obesity in New York City. Environ Health Perspect 2009;117:442-7.

37 Hajna S, Ross NA, Dasgupta K. Steps, moderate-to-vigorous physical activity, and cardiometabolic profiles. Prev Med 2018;107:69-74.

38 Jeon CY, Lokken RP, Hu FB, et al. Physical activity of moderate intensity and risk of type 2 diabetes: a systematic review. Diabetes Care 2007;30:744-52.

39 Janssen I, Katzmarzyk PT, Ross R. Waist circumference and not body mass index explains obesity-related health risk. Am J Clin Nutr 2004;79:379-84.

40 Sriram U, LaCroix AZ, Barrington WE, et al. Neighborhood Walkability and Adiposity in the Women's Health Initiative Cohort. Am J Prev Med 2016;51:722-30. 